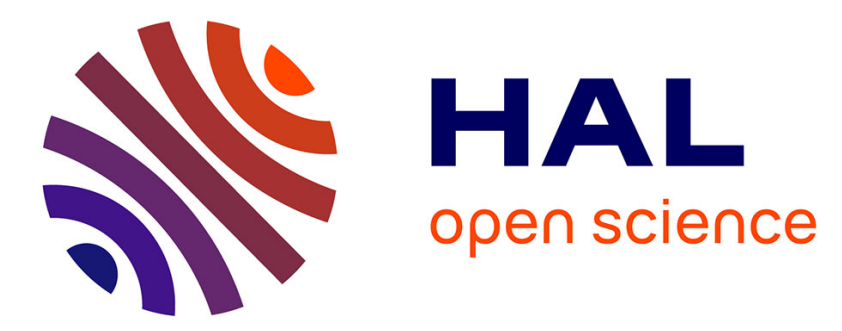

\title{
Sustainable management, earthquake disturbances, and transient dynamics: modelling timber harvesting impacts in mixed-species forests
}

Georges Kunstler, Robert Allen, David Coomes, Charles Canham, Elaine Wright

\section{To cite this version:}

Georges Kunstler, Robert Allen, David Coomes, Charles Canham, Elaine Wright. Sustainable management, earthquake disturbances, and transient dynamics: modelling timber harvesting impacts in mixed-species forests. Annals of Forest Science, 2013, 70 (3), pp.287-298. 10.1007/s13595-012-0256-6 . hal-01201472

\section{HAL Id: hal-01201472 \\ https://hal.science/hal-01201472}

Submitted on 17 Sep 2015

HAL is a multi-disciplinary open access archive for the deposit and dissemination of scientific research documents, whether they are published or not. The documents may come from teaching and research institutions in France or abroad, or from public or private research centers.
L'archive ouverte pluridisciplinaire HAL, est destinée au dépôt et à la diffusion de documents scientifiques de niveau recherche, publiés ou non, émanant des établissements d'enseignement et de recherche français ou étrangers, des laboratoires publics ou privés. 


\title{
Sustainable management, earthquake disturbances, and transient dynamics: modelling timber harvesting impacts in mixed-species forests
}

\author{
Georges Kunstler • Robert B. Allen • David A. Coomes • \\ Charles D. Canham • Elaine F. Wright
}

Received: 20 December 2011 / Accepted: 15 November 2012 / Published online: 18 December 2012

(C) INRA and Springer-Verlag France 2012

\begin{abstract}
- Context There is strong interest in sustainable forest management systems that preserve characteristics of forests close to naturalness. Assessing the effectiveness of these systems is difficult because defining "natural" baselines from which impacts are estimated is challenging and because the influence of harvesting can have complex interactions with major natural disturbances.

- Aims We used SORTIE/NZ, an individual tree-based forest dynamics model, to understand how harvesting and earthquake disturbance affect the dynamics of a New Zealand podocarp-angiosperm forest.

- Methods Having parameterized SORTIE/NZ with extensive field data, we ran simulations for three natural dynamics scenarios (no disturbance and two earthquake scenarios) and then added podocarp harvesting scenario to each of these.
\end{abstract}

Georges Kunstler and Robert B. Allen contributed equally to this work.

Handling Editor: Jean Daniel Bontemps

Contribution of the co-authors R.A., D.C., C.C., and E.W. designed the field work to collect data. G.K., R.A., D.C., and C.C. ran the data analysis and model development. G.K. ran model simulations. G.K. and R.A. wrote the MS.

Electronic supplementary material The online version of this article (doi:10.1007/s13595-012-0256-6) contains supplementary material, which is available to authorized users.

G. Kunstler $(\bowtie)$

IRSTEA, 2 rue de la Papeterie, BP 76 38402, St-Martin-d'Hères, Cedex Grenoble, France

e-mail: georges.kunstler@cemagref.fr

G. Kunstler $\cdot$ D. A. Coomes

Forest Ecology and Conservation Group, Department of Plant

Sciences, University of Cambridge, Cambridge CB2 3EA, UK

R. B. Allen

Landcare Research, P.O. Box 40, Lincoln 7640, New Zealand
- Results Simulations suggest that this forest is experiencing transient dynamics, with a natural rise in the dominance of one species of slow-growing podocarp with and without earthquake. Harvesting podocarps strongly affected its increase in basal area.

- Conclusion Our results indicate that transient dynamics may occur in mixed podocarp forests and major disturbances may have complex interactions with management. Evaluating management impacts without accounting for these complex dynamics may be misleading. Models make predictions about transient trajectories that may help to evaluate these impacts.

Keywords Rare major disturbance - Earthquake · Harvesting · Individual-based model · SORTIE-ND · Transient dynamics

\footnotetext{
C. D. Canham

Cary Institute of Ecosystem Studies, Box AB, Millbrook, NY 12545, USA

E. F. Wright

Department of Conservation, P.O. Box 13-049,

Christchurch, New Zealand

Present Address:

G. Kunstler

Department of Biological Sciences, Macquarie University, Sydney, NSW 2109, Australia
} 


\section{Introduction}

Sustainable forest management is a dominant paradigm in many parts of the world ("Rio Forest Principles"; Tomas 1996; Wiser et al. 2005). One of the objectives of this management is to preserve the structural, compositional, and functional diversity of forests. However, evaluating the effectiveness of management systems is challenging, because "natural" forests have characteristics that may vary with time, making it necessary to emulate the variability of "natural" forest rather than simply focusing on mean characteristics (Millar and Woolfenden 1999). Usually, the short-term impact of management on forest characteristics is evaluated against the range of "natural" variability defined either with direct observations in natural forests or with palaeoecological records of ecosystems before human impacts (Millar and Woolfenden 1999).

Forest ecosystems may exhibit multiple successional pathways (Savage et al. 2000), with long-lasting legacies of forest history (Davis 1986) and unpredictable effects of disturbances interacting with management (Uriarte et al. 2009). The evaluation of management systems against the natural range of variability - challenging though that is may still be too simplistic to cope with this complex dynamics of forest ecosystems (Sprugel 1991). Short-term monitoring of management impacts in field experiment may be unable to predict the long-term impacts of management where there are multiple successional pathways and fail to represent the effects of transient dynamics (Coates et al. 2003). In addition, forests have management superimposed on to rare major disturbances, and this has consequences that are not predictable from the study of disturbance or management alone (Uriarte et al. 2009). Models represent the unique alternative to field experiments to evaluate the long-term impact of management systems. However, only recently have advances in the computational power and design of individual-based simulation models allowed the design of models able to predict compositional and structural trajectories for mixed-age and mixed-species forest with natural disturbance interacting with management (e.g., Coates et al. 2003).

We focused on lowland podocarp-angiosperm forests on the South Island of New Zealand which have a mixed-age and mixed-species structure. The long-term impact of harvesting slow-growing, long-lived podocarps (conifers in the family Podocarpaceae which attract timber prices four times that of the co-occurring angiosperm) in these forests is thus extremely difficult to forecast. In addition, the presence of an active fault along the entire length of New Zealand's South Island means earthquakes cause rare major disturbance over large areas (e.g., Vittoz et al. 2001). This kind of rare major disturbance is important for forest composition because it can favor the regeneration of the long-lived canopy podocarp species (Ogden and Stewart 1995) and can thus have unpredictable interactions with forest management. In this paper, we present the structure and evaluate the prediction of SORTIE/NZ, a recently parameterized individual-based forest dynamics simulation model (Kunstler et al. 2009, 2011). Using this model, we then evaluate the long-term impact of both harvesting podocarps and earthquake disturbance. We implemented podocarp harvesting in a way consistent with legal requirements (Ministry of Agriculture and Forestry 2002). We initiated our simulations using the structure and composition of current pristine forests in Fiordland National Park. These conditions capture any historical legacies of past natural disturbance and a history free from harvesting. The critical questions addressed by our research are: (1) does the long-term dynamic of podocarp-angiosperm forests in the southern South Island of New Zealand suggest equilibrium or transient trajectories? (2) Does earthquake disturbance favor the maintenance of current forest composition by favoring podocarps regeneration? (3) What are the long-term impacts of harvesting the relatively high-value podocarps on forest structure and composition? And finally, (4) what effects do interactions between harvesting and earthquake disturbances have on forest structure, composition, and dynamics?

\section{Materials and methods}

\subsection{Study area}

Mixed podocarp-angiosperm forest occurs on uplifted marine terraces $\left(46.4^{\circ} \mathrm{S} 167.2^{\circ} \mathrm{E}, 100 \mathrm{~m}\right.$ asl $)$ in the Waitutu region of Fiordland National Park (12,500 km²), New Zealand. Soils on these marine terraces are generally silt loams and acidic (pH 3.9) (Coomes et al. 2005). The annual rainfall is 2,000 $\mathrm{mm}$, and the mean January and July temperatures are $12{ }^{\circ} \mathrm{C}$ and $5{ }^{\circ} \mathrm{C}$, respectively (Coomes et al. 2005). We focused our work on the seven dominant tree species (Table 1) which represent more than $98 \%$ of the total basal area $\left(\sim 80 \mathrm{~m}^{2} / \mathrm{ha}\right.$ ) (see Coomes et al. 2005 for a detailed description of the forest structure and composition).

\subsection{Model structure and parameterization}

SORTIE/NZ is a spatially explicit, individual tree-based model which elaborates upon SORTIE (Pacala et al. 1996). It was implemented using the freely available SORTIE-ND software (www.sortie-nd.org). In essence, SORTIE/NZ is a simulator which keeps track of millions of individual trees (in three lifehistory stages: seedlings, saplings, and adults) across a virtual landscape (exact tree location at the nearest centimeter), and every time step ( 5 years) updates whether trees have grown, died, or produced new recruits (Fig. 1). The model assumes that size-asymmetric competition for light is a key driver of 
Table 1 List of species included in the simulations and their initial basal area; only the three Podocarpaceae species were harvested
${ }^{\mathrm{a}}$ var. cliffortioides (Hook.f.) Poole

\begin{tabular}{|c|c|c|c|}
\hline Species & Family & Acronym & $\begin{array}{l}\text { Initial basal area }\left(\mathrm{m}^{2} / \mathrm{ha}\right) \text {, } \\
\text { mean (SD) }\end{array}$ \\
\hline
\end{tabular}

\begin{tabular}{|c|c|c|c|}
\hline Dacrydium cupressinum Lamb. & Podocarpaceae & DACCUP & $26.5(1.4)$ \\
\hline Podocarpus hallii Kirk & Podocarpaceae & PODHAL & $9.8(7.1)$ \\
\hline Prumnopitys ferruginea (D. Don) de Laub. & Podocarpaceae & PRUFER & $5.1(2.3)$ \\
\hline Nothofagus solandri ${ }^{\mathrm{a}}$ & Fagaceae & NOTCLI & $5.6(6.16)$ \\
\hline Nothofagus menziesii (Hook. f.) Oerst. & Fagaceae & NOTMEN & $12.9(2.5)$ \\
\hline Weinmannia racemosa L.f. & Cunoniaceae & WEIRAC & $7.5(2.5)$ \\
\hline Metrosideros umbellata Cav. & Myrtaceae & METUMB & $8.1(3.6)$ \\
\hline
\end{tabular}

growth and mortality and assesses at each time-step how much shade each virtual tree casts on neighboring seedlings and saplings and how, in turn, those juveniles respond to being shaded (Fig. 1). New recruits arise when seeds are produced and dispersed by adult trees, provided they make it through the establishment stage which involves surviving as seedlings in function of substrate types (Fig. 1).

We parameterized all of the submodels using field measurements recently undertaken in Waitutu forest (Coomes et al. 2005, 2009; Kunstler et al. 2009). Data on recruitment, growth, and survival of seedlings, and sapling growth were collected on three mapped plots (ranging from 1.4 to $2.25 \mathrm{ha}$ ). For sapling survival and for adult tree growth and survival, we used 560 National Vegetation Survey (NVS) databank plots $(20 \times 20 \mathrm{~m})$ located in the Waitutu area. The model parameters thus represent the current conditions at our study site in terms of climate, soil conditions, and herbivory by introduced red deer (Cervus elaphus scoticus Lönnberg) and brushtail possum (Trichosurus vulpecula Kerr). The basic submodels are summarized in the following sections (see Appendix A for more details).

\subsubsection{Light submodel}

Light availability is predicted for each individual sapling and adult trees and for $2 \times 2 \mathrm{~m}$ grid cells for seedlings as a function of the solar radiation and trees' locations, species, and crown size, using species-specific canopy light transmission parameters (Canham et al. 1999). The distribution of light predicted by SORTIE/NZ on regular grids in the three mapped stands was in agreement with the light distribution measurements on these grids (see Appendix A).

\subsubsection{Recruitment submodel}

Seedling density (individuals per square meter) was predicted as a function of (1) the spatial distribution and sizes of neighboring parent trees using a dispersal kernel and (2) cover of five seedbed substrate types with different favorability: mineral soil, fresh logs, decayed logs, litter, and moss. Species-specific recruitment functions were fitted with an inverse modelling procedure to the density of seedlings ( $<15 \mathrm{~cm}$ in height) in $1-\mathrm{m}^{2}$ quadrats established along
Fig. 1 Schematic diagram showing the major elements of the SORTIE/NZ model that we constructed for the Waitutu Forests, New Zealand. Earthquake disturbance results in seedling, sapling, and adult mortality

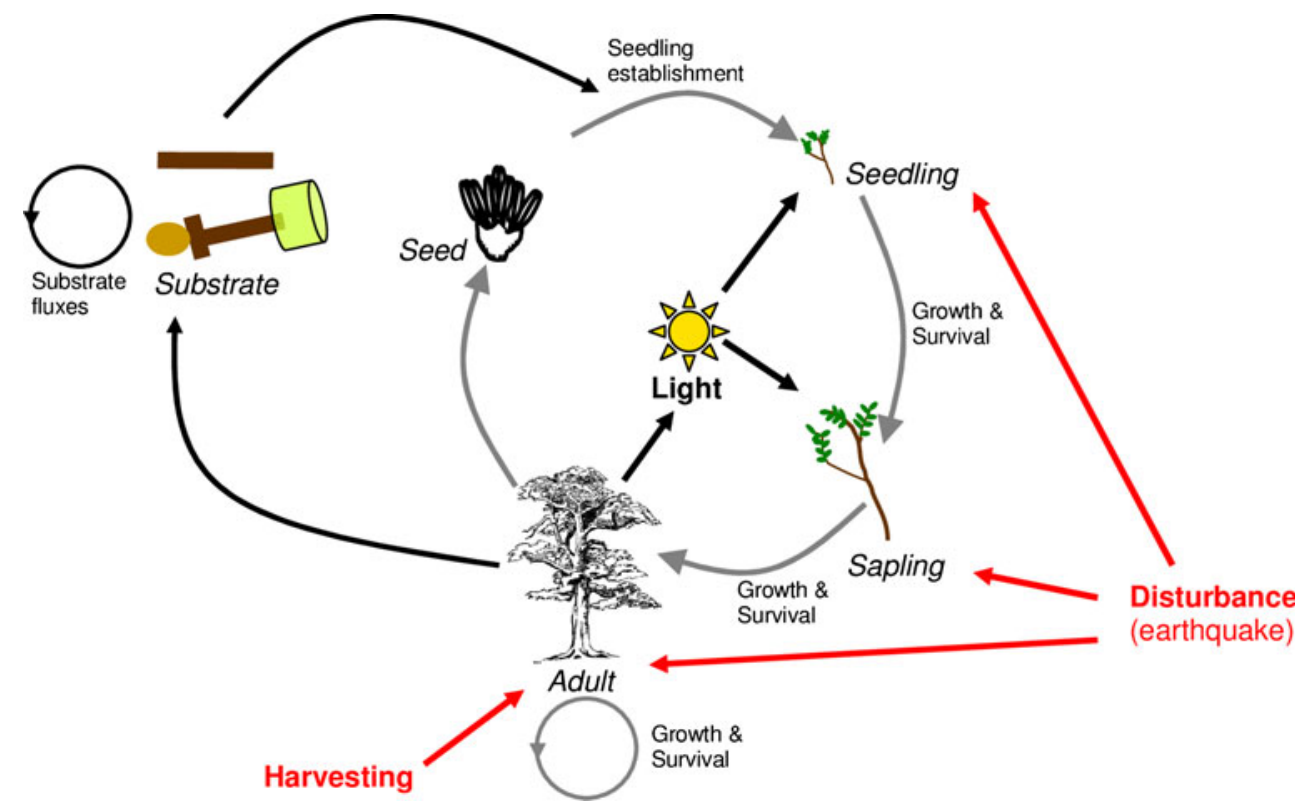


transects in the three mapped stands (Appendix A). The availability of seedbed substrates varied over time in the simulator in response to tree dynamics: Creation is driven by tree mortality (e.g., falling trees create fresh logs). Substrate types decay into other substrates (e.g., fresh logs decay into decayed $\log$ ), using functions fitted with field data (Appendix A). We assumed (as in Pacala et al. 1996) that tree fecundity was identical for all species and all time-steps, because we lacked long-term data to determine speciesspecific fecundity. The fecundity parameter was selected to yield densities of seedlings consistent with field data. Sprouting ability was not explicitly accounted for because it is very uncommon in this site.

\subsubsection{Growth submodel}

Species-specific equations predict growth of seedlings and saplings based upon size and light availability. Seedling $(<1.35 \mathrm{~m}$ in height) growth was based on reassessments of $>7,000$ individuals over a 2-year period (Kunstler et al. $2009)$, and sapling $(0<\mathrm{DBH}<10 \mathrm{~cm})$ growth was estimated from tree ring analysis of 293 individuals (Coomes et al. 2009). Sapling growth parameters were not available for Metrosideros umbellata, but the literature suggests its growth rates are very slow (Payton 1985), so we used parameters from another species with a slow growth rate, Dacrydium cupressinum. Using the 560 NVS plots, speciesspecific non-linear growth equations were estimated from the growth measurements taken on $>10,000$ tagged adult trees ( $\geq 10 \mathrm{~cm} \mathrm{DBH}$ ); growth was modelled as a function of DBH and a measure of local crowding (the basal area of neighbors within a radius of $11.28 \mathrm{~m}$ of the target treebe consistent with the size of NVS plots).

\subsubsection{Mortality submodel}

Seedling mortality was determined as a function of seedling height and light availability for each species using data from $>10,000$ seedlings whose survival was assessed 2 years after being tagged (Kunstler et al. 2009). Average sapling mortality rate per species was estimated using the NVS plots with multiple censuses (Kunstler et al. 2009). Initial runs of the simulator indicated that juvenile densities were unrealistically high, because competition had very little effect on the survival of large seedlings and we had no data with which to model the effects of competition on saplings. We reasoned that our observations were almost certainly underestimating competitive effects, because we had very few large seedlings in our dataset and they occupied a narrow range of light regimes (Kunstler et al. 2009). In order to generate realistic juvenile densities in the simulations, we added a density-dependent mortality function that increased the probability of seedlings and saplings mortality when their density exceeded a given threshold (Appendix A). This function did not change species' survival rankings. Adult tree mortality was determined only as a function of tree DBH because no effect of local crowding was detected in NVS plots data. Survival data from the NVS plots encapsulates the effects of frequent, low-intensity disturbances such local windthrow but not the effect of major disturbances.

\subsubsection{Earthquake disturbance submodel}

The earthquake submodel first simulates the earthquake disturbance with a given return interval and spatial variation in disturbance severity and, secondly, simulates tree (seedling, sapling, and adults) mortality as a function of disturbance severity. Based on Stirling et al. (2002), we used an average return interval of 500 years for a 7.0 moment magnitude index $\left(M_{\mathrm{w}}\right.$; Kanamori 1977) earthquake. The timing of the earthquake disturbance was randomly drawn based on this return interval, and the same occurrence time (at years 405 and 890 of a 1,200-year simulation) was used in all simulations. We applied the same occurrence time to all replicated simulation because earthquake disturbances are likely to affect very large landscape simultaneously and replicated simulations can be seen as multiple stand scale dynamics in such landscape. We parameterized our submodel using remeasurements of 28 NVS plots $(20 \times 20 \mathrm{~m})$ located in Basin Creek forests (the only location with good damage estimates in South Island) after a $6.7-M_{\mathrm{w}}$ earthquake (Allen et al. 1999). Disturbance severity was estimated for each plot as the percentage of stem loss biomass resulting from the earthquake. SORTIE/NZ simulated patch-scale variation by randomly drawing from the distribution of disturbance severities estimated with the Basin Creek data. We tested the sensitivity of the model by applying the severity index to two different patch sizes: $20 \times 20$ and $100 \times 100 \mathrm{~m}$ within a $300 \times 300 \mathrm{~m}$ forest simulation stand. Only Nothofagus solandri is found in Basin Creek. Clearly, species may differ in their susceptibility to earthquake damage, but it was not possible to estimate species-specific parameters with data currently available, so the disturbance response of $N$. solan$d r i$ was applied to all species.

\subsection{Ecological strategies of species}

To summarize the ecological performance of each species in SORTIE/NZ, we calculated five simple metrics: (1) seedling low-light survival, (2) sapling high-light height growth, (3) seedling high-light height growth, (4) probability of dispersal at 100-m distance from parent tree, and (5) amount of shade cast by a tree (Appendix B). There was a clear tradeoff between seedling low-light survival and sapling highlight height growth, with $N$. solandri the most lightdemanding and Podocarpus hallii the most shade-tolerant 
species (Appendix B). D. cupressinum was the species with the best performance in several key aspects of tree ecological strategy. It was one of the most shade-tolerant species but also had a relatively rapid growth as a seedling (Appendix B), resulting in high sapling recruitment rates even in high-light conditions (Kunstler et al. 2009). It had the highest probability of dispersal over longer distances, differing markedly from $N$. solandri, which was the most dispersal-limited species (Appendix B).

\subsection{Setup of the simulations}

All simulations used $300 \times 300 \mathrm{~m}$ composite stands and ran for 1,200 years and thus spanned more than one generation of even the longest-lived trees (podocarps $\sim 1,000$ years). There were 100 replicate runs for each scenario to account for model stochasticity and variability of the initial conditions (see below). We simulated three scenarios of natural forest dynamics: (1) no earthquake disturbance; (2) earthquake disturbance acting on patch size of $20 \times 20 \mathrm{~m}$; and (3) earthquake disturbance acting on patch size of $100 \times 100 \mathrm{~m}$. We then added podocarp harvesting to each of these scenarios, to assess the long-term impact of timber extraction and its effects when superimposed on earthquake disturbance. The results were summarized by plotting the trend in basal area of each species over time and DBH distributions of each species at 600 and 1,200 years.

In our simulations, management was applied as a periodic harvest of podocarp by removing every 10 years: (1) $5 \%$ of basal area of trees with a DBH $>30 \mathrm{~cm}$ and $\leq 90 \mathrm{~cm}$ and (2) $2.5 \%$ of podocarp basal area for trees with a DBH> $90 \mathrm{~cm}$. This management follows the 1993 amendments to the New Zealand Forests Act (1949) and guidelines (Ministry of Agriculture and Forestry 2002). The Act requires for podocarps that: (a) typically $5 \%$ of live standing basal area may be harvested every 10 years, (b) harvesting only trees $>30 \mathrm{~cm}$ in DBH, (c) a proportion of the largest trees shall be retained as wildlife habitat, and (d) trees shall be harvested as individuals or small groups of up to five trees (we only implemented individual tree harvesting).

It was important to initiate our simulation with forest stands similar to those found in the Waitutu area, to capture any historical legacies of past natural disturbance and a history free from harvesting. Data from the three mapped stands were used to generate random $300 \times 300 \mathrm{~m}$ stands with tree spatial distribution, density, and size patterns for species similar to the mapped stands (see Appendix A). The DBH distribution and the range of variability generated over 100 different draws are shown in Fig. 2. The mean total basal area of the initial composite stands was ca. $80 \mathrm{~m}^{2} \mathrm{ha}^{-1}$, one third of which was $D$. cupressinum. The initial abundance of saplings was also simulated for each species based on the NVS plots data. Because we lacked long-term data on seedling density, we set the initial seedling density as the same average value for all species (this had no lasting effect, as changing the initial seedling density affected only the first few years of the simulation).

\subsection{Model evaluation}

Quantitative evaluation of individual-based models of forest dynamics is difficult because long-term field data are rarely available. We evaluated the model prediction over a relatively short period, based on quantitative comparisons with data from NVS plots (70 plots selected to be closely similar to the conditions of the three mapped stands used for parameterisation) for two censuses in 1978 and 1997. We initialized the simulation based on the mean basal area of the seven species on the 70 NVS plots located in the Waitutu area measured in 1978 . We generated $500100 \times 100 \mathrm{~m}$ composite stands with average basal area equal to the NVS plots mean. We ran simulations with $100 \times 100 \mathrm{~m}$ plots to avoid the strong edge effect associated with $20 \times 20 \mathrm{~m}$ plots and ran the model for 19 years. We assessed the goodness-of-fit of species basal area at the end of the simulations with NVS plots mean basal area in 1997 with Pearson's chi-square with a Monte Carlo Pvalue. Supplementary Appendix $C$ shows that model predictions were not significantly different from the observed data. This provides support for short-term predictions of the model.

We also evaluated the model using a sensitivity analysis for two sets of parameters not estimated using field data: Species have identical fecundity parameters, and species have identical resistance to earthquake disturbance. Supplementary Appendix D reports methods and results of this sensitivity analysis and shows that changes in these two sets of parameters had little impact on forest dynamics.

\section{Results}

\subsection{Undisturbed natural forest dynamics}

Simulations of undisturbed natural forest dynamics showed a strong shift from the initial forest composition toward dominance of D. cupressinum (Fig. 3a). Longer simulations, not shown here, eventually resulted in stands with only this species. The total basal area decreased for the first 400 years (Appendix E and Fig. 3a). After this phase, basal area was low for all species except $D$. cupressinum (Fig. 3a), which increased in abundance and was largely dominant in the first DBH class (Fig. 4a). By 1,200 years, D. cupressinum was the dominant tree species with a basal area over $64 \mathrm{~m}^{2} \mathrm{ha}^{-1}$. Only Nothofagus menziesii, M. umbellata, Weinmannia racemosa, and $P$. hallii maintained a basal area above zero. By 600 years, all species except Prumnopitys ferruginea 
Fig. 2 Initial conditions for adult average stem density (individuals per hectare; logarithm scale), in 20-cm DBH-classes (i.e., 20 corresponds to DBH-class 10 $30 \mathrm{~cm}$ ), for each tree species. Also given are upper $95 \%$ quantiles for each DBH-class over the 100 different simulated stands generated with the initial-conditions submodel. Abbreviations are as in Table 1

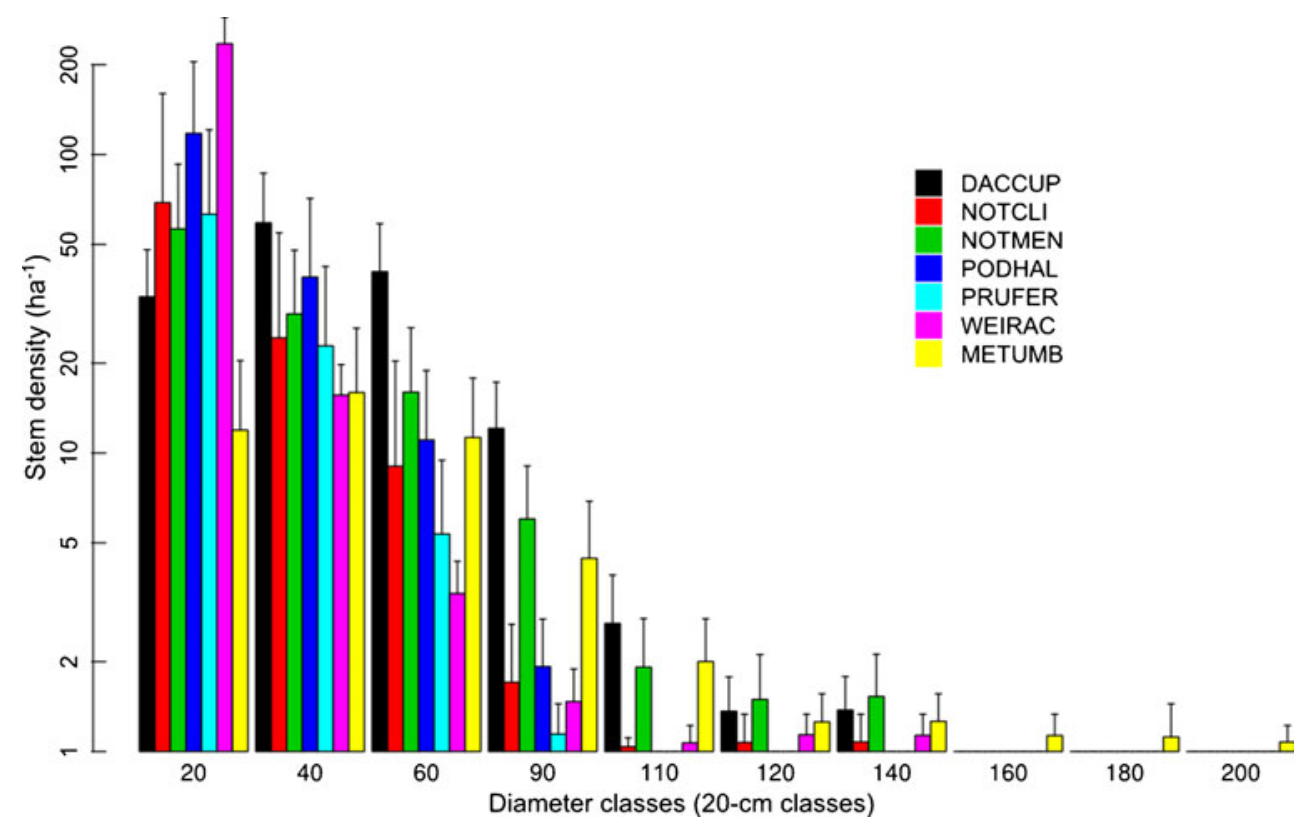

had large trees (>50 $\mathrm{cm}$ of DBH) (Fig. 4a), but by 1,200 years only D. cupressinum and M. umbellata were able to maintain such large trees (Fig. 4g). Even if the longterm dynamics of $D$. cupressinum were sensitive to the

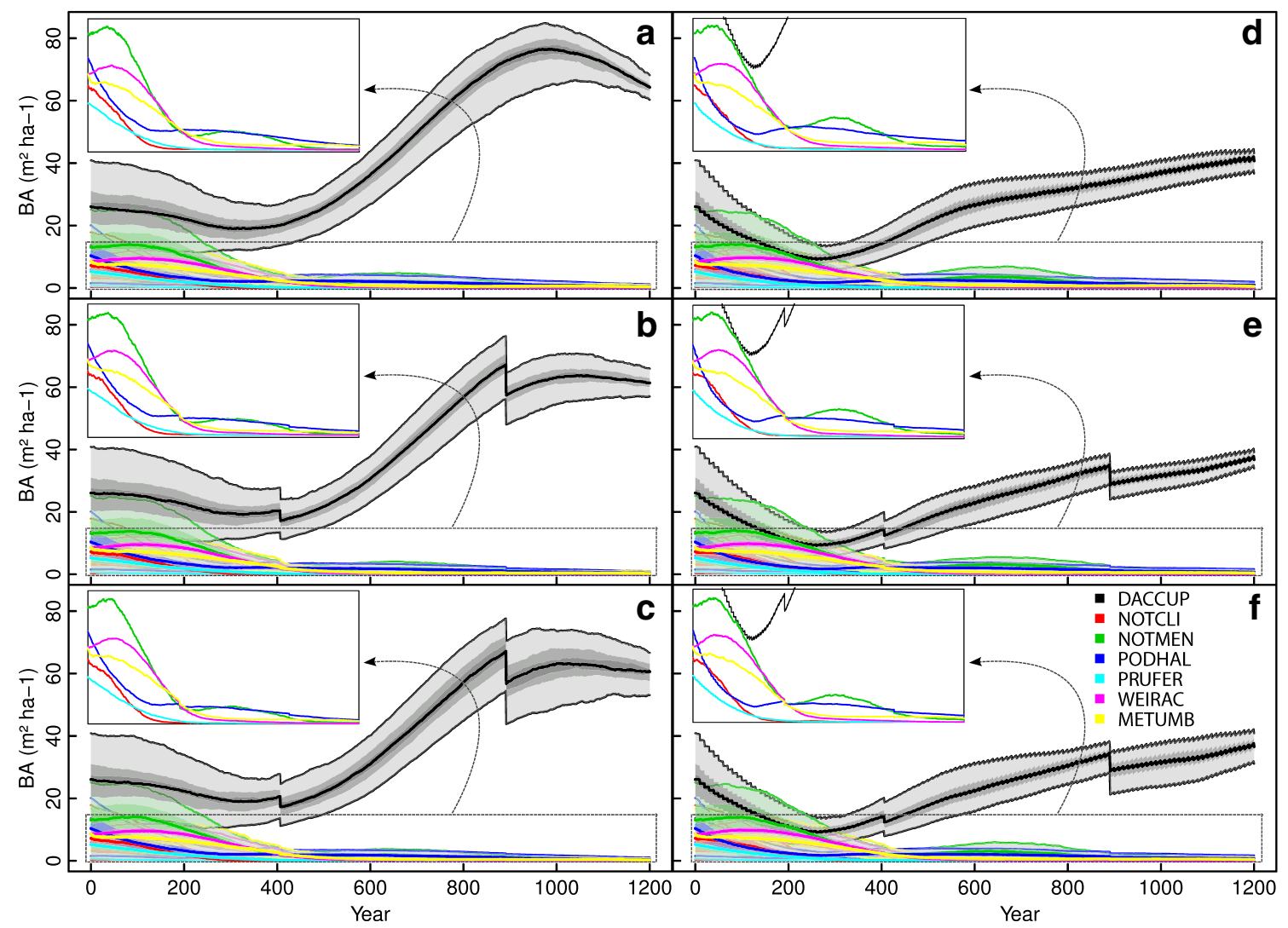

Fig. 3 Trends in median basal area (from 100 simulation runs) for each tree species over 1,200 years for undisturbed natural forest dynamics runs without earthquakes (a) and runs with earthquake disturbance of $20 \times 20 \mathrm{~m}$ patches (b) and $100 \times 100$ patches (c) and for runs with periodic podocarp harvest without earthquakes (d), and runs with periodic podocarp harvest and earthquake disturbance of $20 \times 20 \mathrm{~m}$ patches (e) and $100 \times 100$ patches (f). The colored areas of decreasing shading represent respectively the 40-60 \%, 25-75\%, and 2.5-97.5\% quantiles based upon 100 simulations. A focus on the trends in median basal area of low abundance species (without the shading for simplicity) is shown for each scenario. Abbreviations as in Table 1 
initial conditions (with wide $95 \%$ quantile envelopes, Fig. 3a), this species was dominant in terms of basal area in all 100 simulations. $N$. solandri and $W$. racemosa were almost completely absent in the first DBH class at the end of the simulation (Fig. 4g), indicating that regeneration was insufficient to for the species to maintain. In agreement with its high survival in shade (Appendix B), P. hallii was still present in the first DBH class (Fig. 4g).

\subsection{Earthquake disturbance}

Earthquakes resulted in an immediate drop in basal area of all species, with a strong impact on abundance and size structure of the dominant species D. cupressinum (Fig. 3b, c) with a lower basal area of this species after 600 years than in undisturbed runs (Fig. 5a, b, and c), but the overall dynamics were not strongly affected. $D$. cupressinum still increased in basal area despite the earthquake disturbance (Fig. 3b, c). Earthquake disturbance had a positive effect on $N$. menziesii by maintaining some very large trees $(>90 \mathrm{~cm})$ at the end of the simulation (Fig. 4h, i) when compared with undisturbed forest. By 600 years, the $100 \times 100 \mathrm{~m}$ disturbance also promoted the basal area of $N$. menziesii and $N$. solandri in comparison with undisturbed runs (Fig. 5a, b, and c). In addition, the $100 \times 100 \mathrm{~m}$ disturbance delayed the time until exclusion of $N$. solandri (50 years later) and increased the final basal area of N. menziesii (Fig. 5i).

\subsection{Harvesting}

The most notable difference in species' basal-area trajectories for harvesting simulations, compared with those based on undisturbed natural forest dynamics simulations, is the greater initial decline and lower final basal area reached by D. cupressinum (a decrease of $24 \mathrm{~m}^{2} \mathrm{ha}^{-1}$ in the final basal area, Fig. 3d). In the long-term, P. ferruginea was also negatively affected by harvesting (Fig. 5j). This contrasts with the basal areas of $P$. hallii, which was positively affected by the harvesting in comparison with undisturbed natural forest dynamics simulations (slightly at 600 years (Fig. 5d) but up to $200 \%$ for the final basal area: Fig. 5j). The $95 \%$ quantile envelope of $D$. cupressinum basal area was much narrower than in the undisturbed natural forest simulations, indicating a low sensitivity of its basal area decline to the initial conditions (Fig. 3d). The reduction of D. cupressinum also paralleled an increase in the basal area of $N$. menziesii, which peaked in basal area around 600 years (Fig. 5d) and reached a higher final basal area (Fig. 5j) in the harvesting simulations than for undisturbed natural forest dynamics simulations, but this species remained rare (Fig. 3a versus Fig. $3 \mathrm{~d}$ ). The higher density of $N$. menziesii and $P$. hallii in the first DBH class indicate that, by reducing competition, harvesting improved their regeneration (Fig. $4 \mathrm{~g}$ versus
Fig. 4j). There was also a positive effect on the rare lightdemanding $N$. solandri, which reached a higher basal area at time step 600 years but was still completely excluded at the end of the simulation (Fig. $5 \mathrm{~d}$, j). Total stem density and the range of DBH for all three podocarps were reduced at the end of the harvesting simulations in comparison with the undisturbed natural forest dynamics simulation, particularly for $D$. cupressinum (Fig. 4g versus Fig. 4j).

\subsection{Interactions between harvesting and earthquakes}

The simulations that superimposed podocarp harvesting on earthquake disturbance resulted in moderate positive and negative interactive effects (Fig. 3e and f) in comparison with simulations with disturbance alone (Fig. $3 \mathrm{~b}$ and c). P. ferrugi$n e a$, which was virtually absent from the harvesting-only runs, reached a greater final basal area when earthquake disturbance was added to harvesting (Fig. 5j, k, and 1). This contrasts with decrease of $P$. ferruginea final basal area as a result of disturbance without harvesting (Fig. $5 \mathrm{~g}$, h, and i). Conversely, by 600 years, the basal area of $N$. menziesii and $N$. solandri was promoted by $100 \times 100$-m disturbances without harvesting, but this effect disappeared in the presence of harvesting (Fig. $5 \mathrm{~d}$ versus $5 \mathrm{a}$ and Fig. $5 \mathrm{f}$ versus Fig. 5d).

\section{Discussion}

\subsection{Evaluation of simulations}

It is difficult to evaluate the long-term predictions from forest dynamics models (Uriarte et al. 2009), because field observations are available from too short a timescale (typically a few decades at most) to characterize long-term forest dynamics. Notwithstanding that, our quantitative evaluation using permanent plot data validated predictions of the model over a time scale of 20 years. In addition, our sensitivity analysis of the fecundity parameters showed that the predicted trends were robust to our assumption of identical fecundity for all species. When variability in fecundity was included, D. cupressinum still dominated at the end of the simulation (Appendix D). At the regional scale, pollen analyses reveal a trend of increased dominance of $N$. menziesii over such podocarps in south-western South Island (McGlone and Wilmshurst 1999). However, pollen studies (McGlone and Bathgate 1983; McIntyre and McKellar 1970) also indicate that D. cupressinum can become the dominant species on infertile and poorly drained sites, such as the ancient marine terraces studied by us, because Nothofagus is unable to outcompeted podocarps under these conditions (Coomes and Bellingham 2011). Consequently, our model's prediction of increasing dominance by $D$. cupressinum and slow exclusion of other species is consistent with 

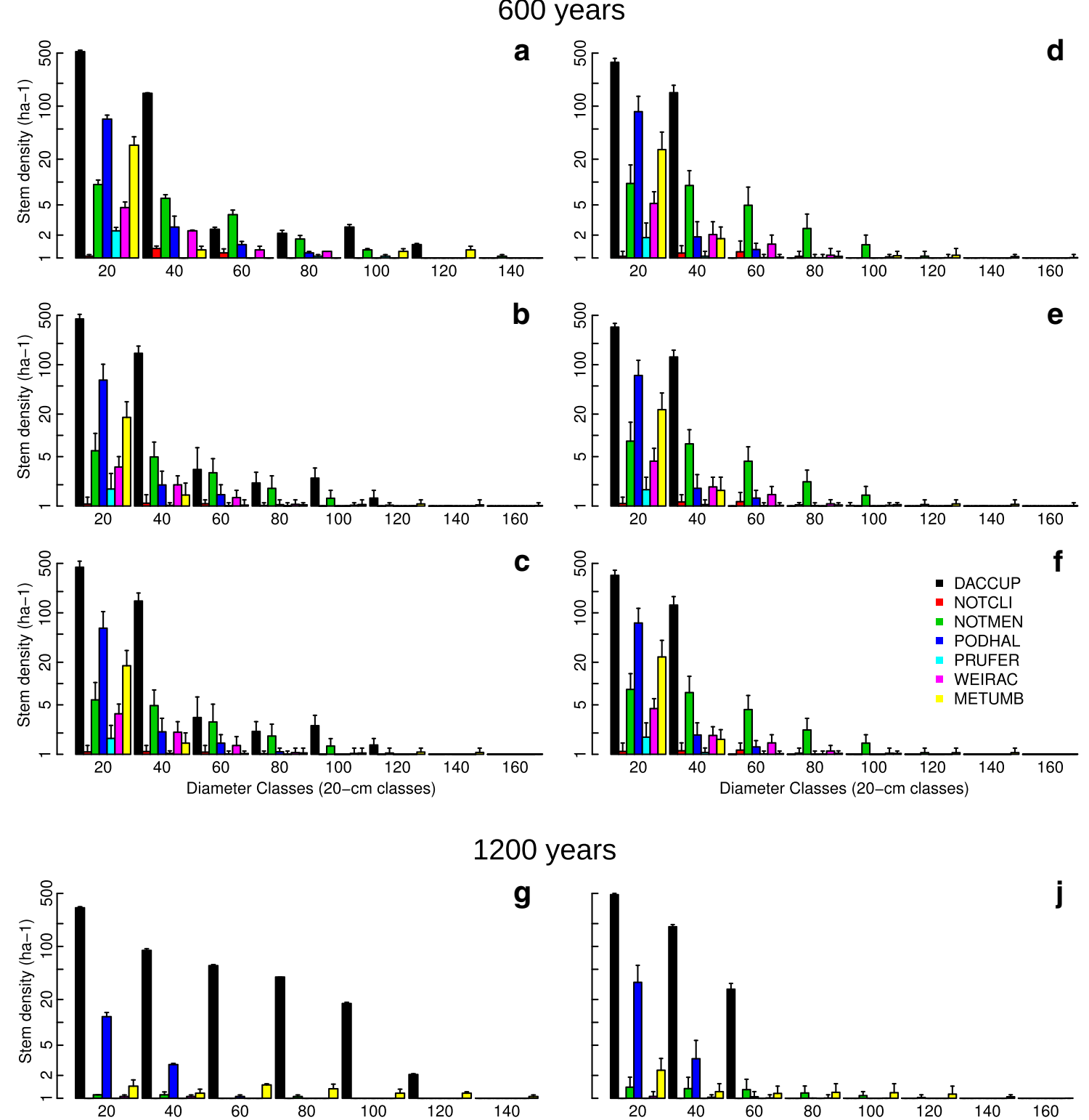

years
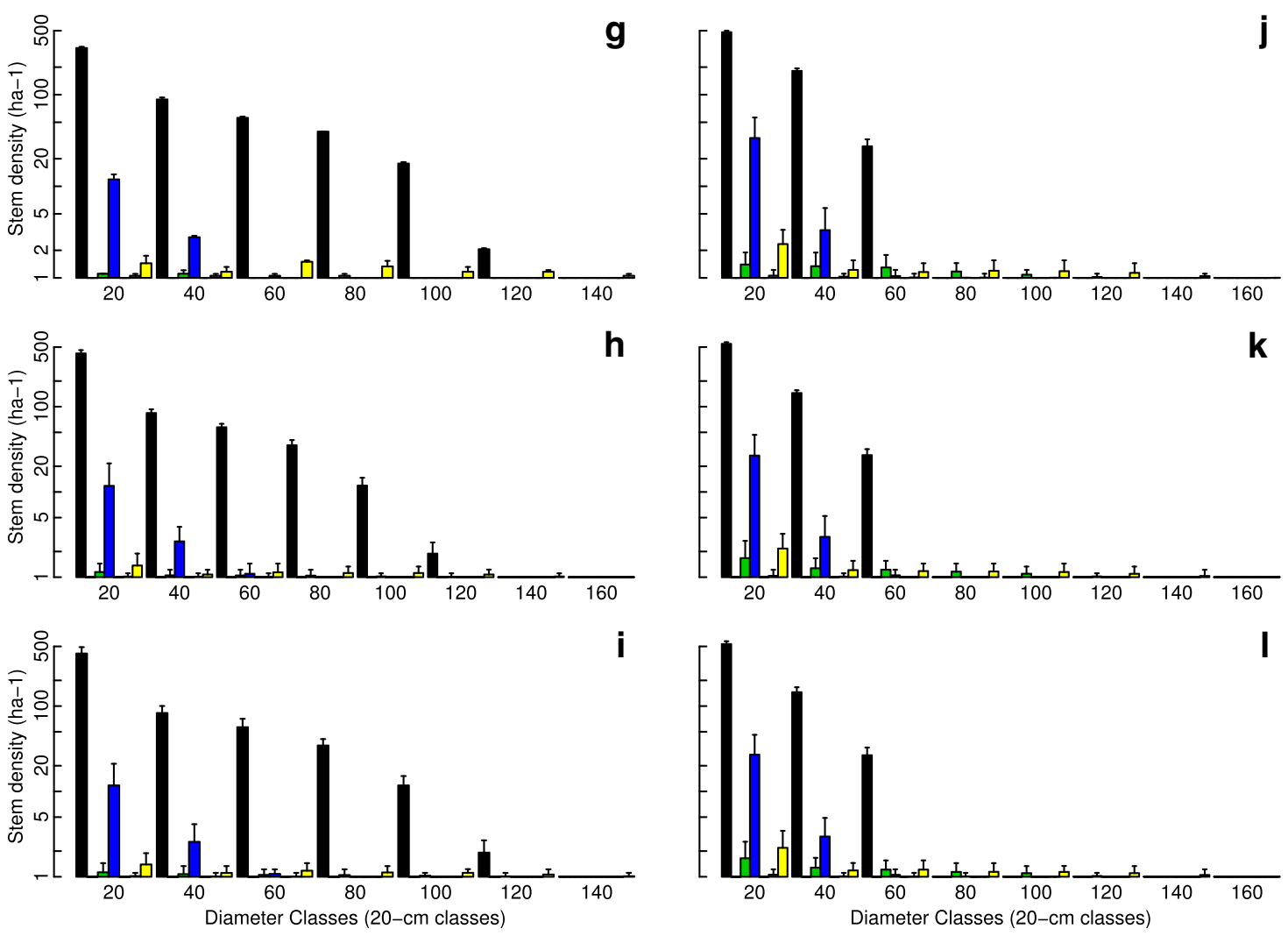
600 years

a

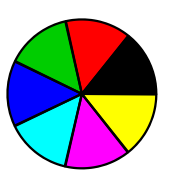

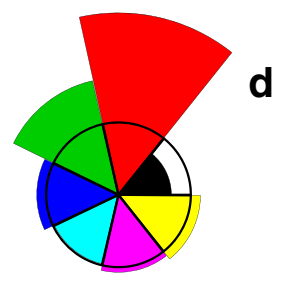

- DACCUP I PRUFER

- NOTCLI - WEIRAC

- NOTMEN METUMB

b
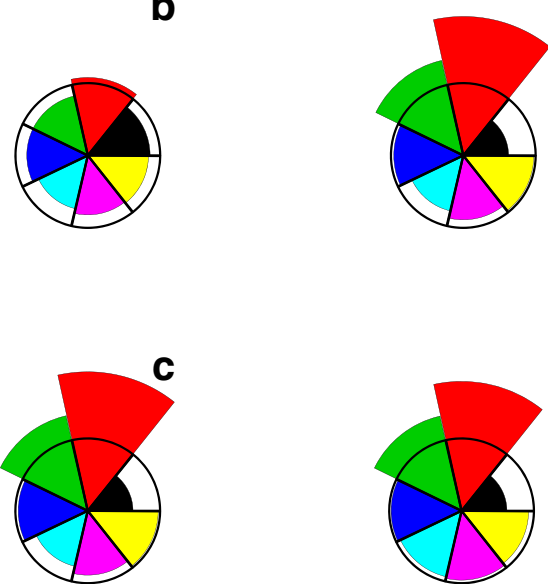

e

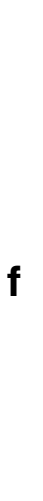

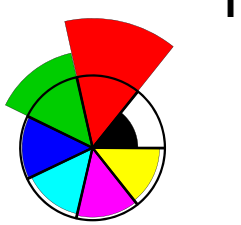

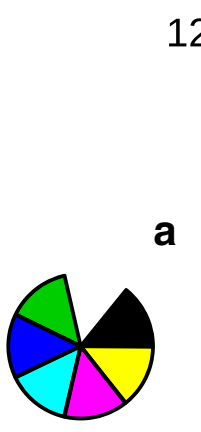

1200 years

a

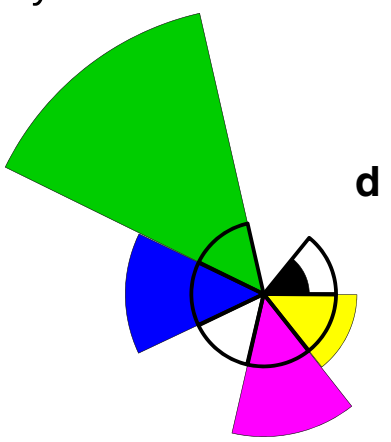

b
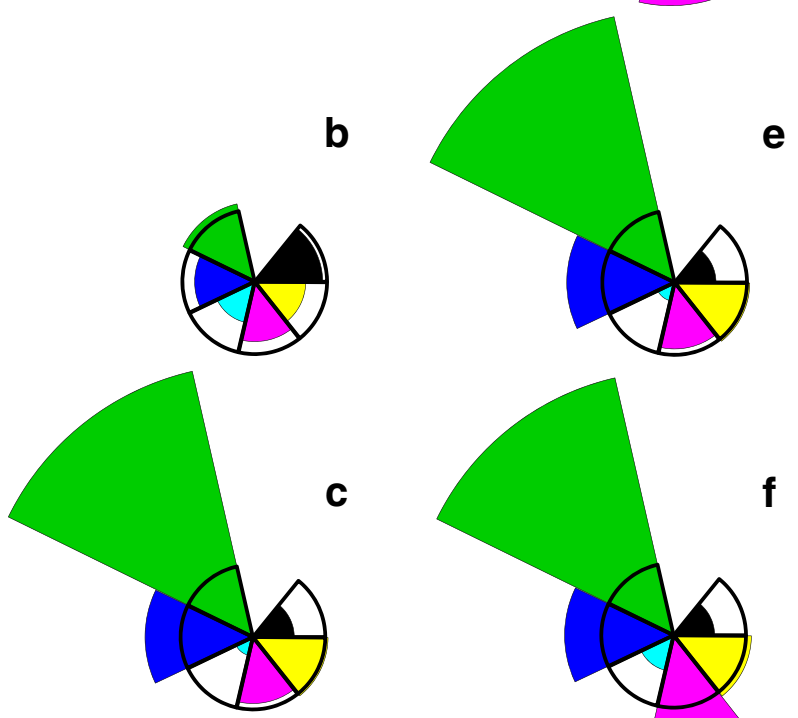

C

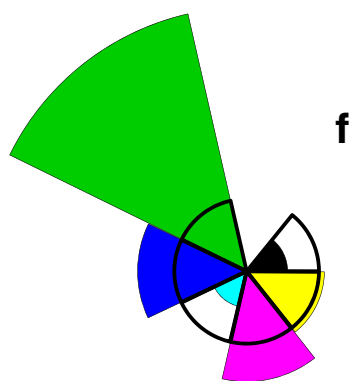

f

Fig. 5 Segment diagrams showing relative change in species basal area in comparison to undisturbed natural forest dynamics runs at 600 and at 1,200 years for various simulation runs. The radius of the segment for each species represents species median basal area relative to that species' basal area from undisturbed runs; the black circle represents 1 , thus no change in comparison with basal area from undisturbed natural runs.

expectations (Coomes et al. 2005). The predictions are also in agreement with earlier simulation studies using an ecosystem process model, which also showed a dominance of D. cupressinum on particular sites in south-western South Island (Hall and Hollinger 2000; Hall and McGlone 2001).

Evaluating the model's predictions regarding earthquake disturbance response is even more problematic because data on major disturbance impacts are scarce or indirect. A common approach has been to analyze forest stand history based on indirect measurements such as the age structure or

Fig. 4 Stem density (individuals per hectare; logarithm scale), in 20-cm DBH-classes at 600 and 1,200 years, for each tree species for natural forest dynamics runs without earthquake disturbance ( $\mathbf{a}$ and $\mathbf{g}$ ), and runs with earthquakes disturbance of $20 \times 20 \mathrm{~m}$ patches $(\mathbf{b}$ and $\mathbf{h})$ and $100 \times$ 100 patches (c and i) and for runs with periodic podocarp harvest without earthquakes ( $\mathbf{d}$ and $\mathbf{j}$ ), and runs with harvest and earthquakes disturbance of $20 \times 20 \mathrm{~m}$ patches $(\mathbf{e}$ and $\mathbf{k})$ and $100 \times 100$ patches $(\mathbf{f}$ and $\mathbf{~})$. Also given are upper $95 \%$ quantiles for each DBH-class based upon 100 simulations. Abbreviations as in Table 1

Segment diagrams are for simulation runs of undisturbed natural forest dynamics runs without earthquakes (a and $\mathbf{g}$ ) and runs with earthquakes disturbance of $20 \times 20 \mathrm{~m}$ patches (b and $\mathbf{h})$ and $100 \times 100$ patches (c and i) and for runs with podocarp harvest without earthquakes ( $\mathbf{d}$ and $\mathbf{j}$ ), and runs with harvest and earthquakes disturbance of $20 \times 20 \mathrm{~m}$ patches (e and k) and $100 \times 100$ patches (f and $\mathbf{l})$

spatial distribution of individuals. In our simulations, the abundances of $N$. solandri and $N$. menziesii responded positively to earthquake disturbance, with $N$. solandri showing a strong pulse of recruitment after disturbance. This prediction agrees with analyses of stand structure (Vittoz et al. 2001) and those made by another simulation model based on different data (Hall and Hollinger 2000). As a consequence, earthquake disturbance resulted in higher canopy species diversity. In contrast, for three podocarp species, $D$. cupressinum, P. ferruginea, and P. hallii, earthquake disturbance simulations predicted a decline in basal area, a pattern that was insensitive to the grain size of the disturbance. This result is surprising because it is generally believed that regeneration of these podocarps is enhanced by disturbance, leading to cohort-driven age structures (Ogden and Stewart 1995). However, the literature on this issue is conflicting, and some studies (Allen and Norton 2001; Carswell et al. 2007; Lusk and Ogden 1992) have concluded that podocarp 
regeneration is not necessarily promoted by disturbance. We cannot exclude a possibility that our model, centered on competition for light, lacks some process allowing podocarp post-disturbance regeneration.

\subsection{Transient forest dynamics and increased dominance of $D$. cupressinum}

The long-term dynamics predicted by our no-disturbance simulation model suggest significant changes will occur in the structure and composition of Waitutu Forest, with a longterm significant increase of $D$. cupressinum basal area. Our simulations with earthquake disturbance show a similar pattern of increasing dominance of this species. Even if the addition of this disturbance favored the abundance of rare species and delayed the time of exclusion of some species, disturbance did not preserve the initial forest composition. Thus, even with disturbance, the simulations predict large changes in forest structure and composition marked by the progressive competitive exclusion of most species by $D$. cupressinum. The analysis of the ecological strategies of the tree species explains this dynamics, as $D$. cupressinum is a species with strong performance in both shade and high light conditions, and high dispersal ability. Its relatively high shade tolerance in this low-fertility site resulted in a progressive increase in abundance of this species in small size classes and allowed it to eventually dominate size classes above $60 \mathrm{~cm}$ of DBH. Note that it will probably not be able to dominate under the deeper shade cast by dense forest on richer soil (Coomes and Bellingham 2011). This implies that the present structure of the forest at Waitutu area is not stable and may be the legacy of past conditions. Several nonmutually exclusive factors can explain the present structure: past variation in climate (for instance, a shift to cooler winters and drier summers around 3,500 years before present) that may have favored species not matched to current climate; there may be an incomplete adjustment to past large-scale disturbance (e.g., glaciation) or ongoing variation in local canopy disturbance regimes (e.g., McGlone et al. 1996).

\subsection{Impacts of podocarp harvesting}

Podocarp harvesting had a negative effect on D. cupressinum but positive effect on the non-harvested angiosperms. More surprisingly, the overall impact of podocarp harvesting was positive for $P$. hallii- one of the harvested podocarp species. Our results suggest these positive effects of harvesting result from a release from $D$. cupressinum competition. In effect, harvesting of selected species can have non-trivial effects on overall composition by changing the network of competitive interactions. Simulation studies in tropical forests have reported that tree species may also differ in their response to harvesting because of differences in initial abundance or size structure (Huth and Ditzer 2001). Our results support the view that sustainable management of mixed-species forests requires a clear understanding of tree species' competitive interactions and how they are altered by harvesting operations (Wiser et al. 2005). Harvesting does not appear to merely substitute for earthquake disturbance, because the negative effect of harvesting on final basal area of $D$. cupressinum was more severe than with earthquake (Fig. 3b, c, and d). Harvesting also strongly affected the abundance of large DBH podocarps trees, with an almost complete disappearance of podocarps $>50 \mathrm{~cm} \mathrm{DBH}$, which was not the case after earthquake disturbance.

\subsection{Harvesting effects interact with earthquakes}

Superimposing earthquake disturbance on harvesting demonstrated both positive interactions (e.g., a greater positive effect of disturbance on P. ferruginea basal area with harvesting than without) and negative interactions (e.g., a negative effect of disturbance on $N$. solandri and $N$. menziesii basal area with harvesting compared with the positive effect observed without harvesting). For Nothofagus, the overall effect likely shifted to negative because harvesting was already favoring regeneration of these species. Such results supports the view that harvesting and natural disturbance can interact in ways not predictable from the analysis of disturbances or harvesting alone (Uriarte et al. 2009). Compounded natural and anthropogenic disturbances can lead to complex effects resulting in "ecological surprises" (Paine et al. 1998), and such effects need to be included in the evaluation of forest management systems.

\subsection{Evaluating forest management when forest structure is naturally dynamic}

Our simulations show that the natural forests we studied are not in dynamic equilibrium and cannot be used as a simple reference against which to evaluate forest management impacts. As a consequence of the legacies of natural (Foster et al. 1998) and human (Dupouey et al. 2002) disturbances, and the legacies of past and ongoing climate change (Millar and Woolfenden 1999), we can expect that most forests around the world are not in a stable state and that their trajectories are highly uncertain. As Shinneman and Baker (1997) point out, forest management plans that endorse an equilibrium view are likely to be misdirected. According to the equilibrium view, the objectives of the management systems should be to conserve a structure similar to existing natural forests. However, as natural forests may experience transient dynamics, it may be more desirable to preserve species diversity and composition and forest structure linked to key ecological functions (for instance, large trees hosting associated forest biodiversity, or a mixture of leaf composition promoting efficient nutrient cycling). 


\section{Conclusion}

We have shown that a forest dynamics model can be a useful tool to evaluate management systems while accounting for the complexity of forest dynamics. By demonstrating that the natural forests under consideration are undergoing transient dynamics, our simulations established a baseline against which management effectiveness can be assessed without an equilibrium assumption. The model allows us to account for potential interactions between management and natural disturbance in the evaluation. Of course, because every model contains simplifications, predictions have uncertainties and their use in evaluating management systems needs to account for this uncertainty. This means that data from monitoring of natural and managed forests and palaeoecological records of ecosystems before and after human impacts are also extremely valuable, but they need to be analyzed while keeping in mind that these systems are dynamic. The main contribution of our model is to help understand how management systems influence and interact with natural trajectories. With such tools, sustainable forest management can accommodate both historical legacies and compounded effect of natural perturbations and harvesting.

Acknowledgments Many staff at Landcare Research and Department of Conservation contributed data towards the Waitutu Ecosystem Project. We are grateful to Lora Murphy for the development of SORTIE-ND. We are grateful for comments made by T. Cordonnier, J. Caspersen, N. Mason, M. McGlone, P. Bellingham, A. Griffiths, and C. Bezar.

Funding Funding was provided by New Zealand's Foundation for Research, Science and Technology, Department of Conservation, Ministry of Agriculture and Forestry \& Landcare Research, as well as by the Natural Environmental Research Council in the UK.

\section{References}

Allen RB, Norton DA (2001) Disturbance ecology: a basis for sustainable forest management. In: Stewart GH, Benecke U, Hickey J (eds) Proceedings of a symposium: sustainable management of indigenous forest, Southern Connections Congress III. Wickliffe Press, Christchurch, pp 16-23

Allen RB, Bellingham PJ, Wiser SK (1999) Immediate damage by an earthquake to a temperate montane forest. Ecology 80:708-714

Canham CD, Coates KD, Bartemucci P, Quaglia S (1999) Measurement and modeling of spatially-explicit variation light transmission through interior cedar-hemlock forests of British Columbia. Can J For Res 29:1775-1783

Carswell FE, Richardson SJ, Doherty JE, Allen RB, Wiser SK (2007) Where do conifers regenerate after selective harvest? A case study from a New Zealand conifer-angiosperm forest. For Ecol Manag 253:138-147

Coates DK, Canham CD, Beaudet M, Sachs DI, Messier C (2003) Use of a spatially explicit individual-tree model (SORTIE/BC) to explore the implications of patchiness in structurally complex forest. For Ecol Manag 186:297-310

Coomes DA, Bellingham PJ (2011) Temperate and tropical podocarps: how ecologically alike are they? In: Turner BL, Cernusak LA (ed)
Ecology of Podocarpaceae in tropical forests. Smithson Contrib Bot 95:119-140

Coomes DA, Allen RB, Bently WA, Burows LE, Canham CD, Fagan L, Forsyth DM, Gaxiola-Alcantar A, Parfitt RL, Ruscoe WA, Wardle DA, Wilson DJ, Wright EF (2005) The hare, the tortoise, and the crocodile: the ecology of angiosperm dominance, conifer persistence and fern filtering. J Ecol 93:918-935

Coomes DA, Kunstler G, Canham CD, Wright E (2009) A greater range of shade tolerance strategies among species in relatively nutrient-rich forests: a niche-based explanation for positive richness-productivity relationships? J Ecol 97:705-717

Davis MB (1986) Climatic instability, time lags and community disequilibrium. In: Diamond J, Case THE (eds) Community ecology. Harper \& Row, New York, pp 269-284

Dupouey JL, Dambrine E, Laffite JD, Moares C (2002) Irreversible impact of past land use on forest soils and biodiversity. Ecology 83:2978-2984

Foster DR, Knight DH, Franklin JF (1998) Landscape patterns and legacies resulting from large infrequent forest disturbances. Ecosystems 1:497-510

Hall GMJ, Hollinger DY (2000) Simulating New Zealand forest dynamics with a generalized temperate forest gap model. Ecol Appl $10: 115-130$

Hall GMJ, McGlone MS (2001) Forest reconstruction and past climatic estimates for a deforested region of south-eastern New Zealand. Landsc Ecol 16:501-521

Huth A, Ditzer T (2001) Long-term impacts of logging in a tropical rain forest - a simulation study. For Ecol Manag 142:33-51

Kanamori H (1977) The energy release in great earthquakes. J Geophys Res 82:2876-2981

Kunstler G, Coomes DA, Canham CD (2009) Size-dependence of growth and mortality influence the shade tolerance of trees in a lowland temperate rain forest. J Ecol 97:685-695

Kunstler G, Allen RB, Coomes DA, Canham CD, Wright EF (2011) SORTIE/NZ model development. Landcare Research, Lincoln, New Zealand. ISBN : 978-0-473-19799-5. www.landcareresearch.co.nz/ data/assets/pdf file/0010/43759/sortie nz model dev.pdf

Lusk $\bar{C} H$, Ogden J (1992) Age structure and dynamics of a podocarpbroadleaf forest in Tongariro National Park, New Zealand. J Ecol 80:379-393

McGlone MS, Bathgate JL (1983) Vegetation and climate history of the longwood Range, South Island, New Zealand. N Z J Bot 21:293-315

McGlone MS, Wilmshurst JM (1999) A Holocene record of climate, vegetation change and peat bog development, east Otago, New Zealand. J Quat Sci 14:239-254

McGlone MS, Mildenhall DC, Pole MS (1996) History and paleoecology of New Zealand Nothofagus forests. In: Veblen TT, Hill RS, Reid J (eds) The ecology and biogeography of Nothofagus forests. Yale University Press, New Haven, p 403

McIntyre DJ, McKellar IC (1970) A radiocarbon dated post glacial pollen profile from Swampy Hill, Dunedin, New Zealand. N Z J Geol Geophys 13:346-349

Millar CI, Woolfenden WB (1999) The role of climate change in interpreting historical variability. Ecol Appl 9:1207-1216

Ministry of Agriculture and Forestry (2002) Standards and guidelines for sustainable management of indigenous forests. Part IIIA Forest Act 1949, 2nd edn. Ministry of Agriculture and Forestry, Wellington

Ogden J, Stewart GH (1995) Community dynamics of New Zealand conifers. In: Enright NJ, Hil RS (eds) Ecology of the southern conifers. Melbourne University Press, Melbourne, pp 81-119

Pacala SW, Canham CD, Saponara J, Silander JA, Kobe RK, Ribbens E (1996) Forest models defined by field measurements: II. Estimation, error analysis and dynamics. Ecol Monogr 66:1-43

Paine RT, Tegner MJ, Johnson EA (1998) Compounded perturbations yield ecological surprises. Ecosystems 1:535-545 
Payton IJ (1985) Southern rata (Metrosideros umbellata Cav.) mortality in Westland, New Zealand. In: Truner H, Ranquillini W (ed) Proceedings of the IUFRO Workshop 1984: Establishment and Tending of Subalpine Forests: Research and Management. Swiss Federal Institute of Forestry Research Berichte, 270, pp. 207-214

Savage M, Sawhill B, Askenazi M (2000) Community dynamics: what happens when we rerun the tape? J Theor Biol 205:515-526

Shinneman DJ, Baker WL (1997) Nonequilibrium dynamics between catastrophic disturbances and old-growth forests in ponderosa pine landscapes of the Black Hills. Conserv Biol 11:1276-1288

Sprugel DG (1991) Disturbance, equilibrium, and environmental variability: what is 'natural' vegetation in a changing environment? Biol Conserv 58:1-18
Stirling MW, McVerry GH, Berryman KR (2002) A new seismic hazard model for New Zealand. Bull Seismol Soc Am 92:1878-1903

Tomas JW (1996) Forest service perspective on ecosystem management. Ecol Appl 6:703-705

Uriarte M, Canham CD, Thompson J, Zimmerman JK (2009) Understanding natural disturbance and human land use as determinants of tree community dynamics in a subtropical wet forest: results from a forest simulator. Ecol Monogr 79:423-443

Vittoz P, Stewart GH, Duncan RP (2001) Earthquake impacts in oldgrowth Nothofagus forests in New Zealand. J Veg Sci 12:417-426

Wiser SK, Allen RB, Benecke U, Baker G, Peltzer DA (2005) Tree growth and mortality after small-group harvesting in New Zealand old-growth Nothofagus forests. Can J For Res 35:2323-2331 